\title{
Informed decision making about predictive DNA tests: arguments for more public visibility of personal deliberations about the good life
}

\author{
Marianne Boenink · Simone van der Burg
}

Published online: 30 October 2009

(C) The Author(s) 2009. This article is published with open access at Springerlink.com

\begin{abstract}
Since its advent, predictive DNA testing has been perceived as a technology that may have considerable impact on the quality of people's life. The decision whether or not to use this technology is up to the individual client. However, to enable well considered decision making both the negative as well as the positive freedom of the individual should be supported. In this paper, we argue that current professional and public discourse on predictive DNA-testing is lacking when it comes to supporting positive freedom, because it is usually framed in terms of risk and risk management. We show how this 'risk discourse' steers thinking on the good life in a particular way. We go on to argue that empirical research into the actual deliberation and decision making processes of individuals and families may be used to enrich the environment of personal deliberation in three ways: (1) it points at a richer set of values that deliberators can take into account, (2) it acknowledges the shared nature of genes, and (3) it shows how one might frame decisions in a non-binary way. We argue that the public sharing and discussing of stories about personal deliberations offers valuable input for others who face similar choices: it fosters their positive freedom to shape their view of the good life in relation to DNAdiagnostics. We conclude by offering some suggestions as to how to realize such public sharing of personal stories.
\end{abstract}

\footnotetext{
M. Boenink $(\bowtie) \cdot$ S. van der Burg

Department of Philosophy, University of Twente, P.O. Box 217,

7500 AE Enschede, The Netherlands

e-mail: m.boenink@utwente.nl

S. van der Burg

e-mail: s.vanderburg@utwente.nl
}

Keywords DNA-diagnostics - Predictive testing · Uncertainty $\cdot$ Risk $\cdot$ Positive freedom $\cdot$ Negative freedom . Personal stories $\cdot$ Public sphere

\section{Introduction}

Since its advent, predictive DNA testing has been surrounded by extensive ethical analysis and debate. From the outset it was recognized that knowledge about one's future health risks may have serious implications for one's identity and view of the good life. Since the good life is regarded as the object of individuals' personal evaluation and choice, genetic professionals and ethicists alike stressed that people should be able to decide for themselves whether or not to take a test (Bartels et al. 1993; Davison et al. 1994; Gezondheidsraad 1994; Fost 1999; Brody 2002).

In many European countries predictive testing is now offered in a medical setting, with opportunities (or even obligations) to receive individual counseling by a medical or genetic professional. Moreover, in this setting usually a professional policy of non-directiveness in counseling potential clients is advocated (Bosk 1992; Fine 1993). The guiding thought is that such counseling enables individuals to come to well considered individual decisions regarding the use of predictive testing.

In the USA, predictive testing is also commercially available and sold directly to consumers. Via the Internet commercial predictive tests are rapidly becoming available to anyone anywhere-provided one is willing to pay. In the commercial setting decision making with regard to predictive testing is, of course, also delegated to the individual customer. It is interesting to note that some commercial providers also stress the importance of careful deliberation 
in advance of testing and point out, or require, that medical professionals support this process (see for an example www.myriad.com).

Both in the medical and the commercial domain, then, individuals are seen as the ones who should decide whether or not predictive testing fits with their personal views on the good life. This is hardly surprising in liberal societies. It is questionable, however, whether this focus on free personal decision making suffices to enable well considered decisions. 'Freedom of choice' in the context of predictive testing most often seems to be interpreted in negative terms as refraining from interference with personal decision making. However, 'free' means not only being free from interference or outright coercion (negative freedom); freedom is also to be enabled to think or do something (positive freedom) (Berlin 1959, 43 \& 52).

In this paper we want to argue that in the current social context in which decisions about DNA tests have to be taken, individuals' positive freedom is lacking because the starting points offered for individual deliberation on the desirability of predictive testing are seriously impoverished. We will first show how discourse of predictive test providers, whether medical or commercial, is often framed in terms of health risk and risk management. We will then argue that this 'risk discourse' has serious limitations and drawbacks, and tends to neglect or marginalize many alternative values and considerations that might be taken into account. The question then is how we might support individuals and families in their deliberations, without interfering with their actual decisions. In the last section we will argue that recent empirical research on actual deliberation processes of potential clients (individuals and families) may be a source of inspiration for individual decision makers. Finally, in the conclusion we will reflect how such findings might be used to foster well considered decision making without promoting one particular view of the good life.

\section{Current providers' discourse on predictive DNA diagnostics}

In the last 15 years, opportunities for predictive DNA testing have increased enormously. In general, such testing allows healthy individuals to check whether they carry a mutation that predisposes them to a specific disease. By now, predictive testing is available for a range of rare hereditary diseases like Cystic Fibrosis and Huntington's disease, but also for hereditary forms of common diseases like breast and colon cancer, Alzheimer's disease and several cardiac diseases. In addition, an increasing number of pharmacogenomic and nutrigenomic DNA screening tests are offered. These tests check a set of genes, resulting in genetic risk profiles that might be used to predict drug response or to argue for certain dietary or lifestyle recommendations.

The setting in which such tests are offered differs considerably between and sometimes even within countries. The provider may be public or commercial, testing may be offered via medical professionals or directly to consumers, counseling before and/or after testing may be present or absent, testing may be reimbursed or paid for by users, and even the exact technological procedures performed in the lab may differ (see for example Parthasarathy 2005, 2007). As a result, 'having a predictive DNA test' may have completely different meanings in different countries (Boenink 2009).

Notwithstanding these differences, different providers seem to agree to a large extent on the goals and value of predictive DNA testing. We do not claim to present a systematic overview of providers' arguments here, but in the medical as well as the commercial domain many citations can be found that justify predictive testing in terms of knowledge about your future health and of the possibility to counteract potential threats, thus helping to realize the value of health. A strong emphasis is laid on the identification of risks to one's health and life, and the possible ways to act to diminish or take away those risks. Let us give some examples here. ${ }^{1}$

A brochure issued by the Dutch Cancer Society states:

"Genetic diagnostics can help determine whether a family suffers from hereditary cancer. If desired, experts estimate which family members do and which ones do not have an increased risk. Subsequently an indication is given which precautionary measures those with a genetic predisposition may take." (from 'Hereditary breast and ovarian cancer', brochure of the Dutch Cancer Society 2002, p. 11)

Commercial companies also promote their services as a way to master risk. The American company Myriad promotes predictive testing by stating:

"There are ways to reduce your risk or overcome cancer in your lifetime. (...) Genetic testing can give you answers about your risk of inherited cancers by analyzing your genes for mutations responsible for inherited cancer risk. Results will help you make informed decisions about your options for early cancer detection and risk reduction. (...) Regardless of the outcome of your test, your results can help you make positive changes in your life." (http://www.myriad tests.com/consumer_home.htm, accessed at March 7, 2009)

\footnotetext{
${ }^{1}$ Similar statements can be found in brochures of Dutch Centers offering predictive DNA testing, as well as on the websites of companies offering predictive screening tests like www.health anddna.com, www.salugen.com; www.suracell.com.
} 
Finally, Genosolutions, a company offering DNA diagnostic testing via internet, promotes predictive testing by way of analogy:

"It would be very difficult for anyone to win at poker if they were never allowed to see what cards they had been dealt. They would have no way of knowing which cards to keep or which cards to discard. Similarly, until they understand their genetic strengths and weaknesses, through our genomic testing and through our counsel relative to prevention and therapeutic strategies, they won't know how to play the genetic 'hand' life has dealt them. Without that information, there will be no clear way of knowing if clinical interventions are addressing their most important individual risks and needs." (http://www.genosolutions.com/ public_benefits.php, accessed March 6, 2009)

The recurring theme in these citations is that predictive DNA testing enables individuals to be 'pro-active' towards the future by taking 'pre-caution'. Knowledge about one's genetic constitution is thought to enable people to anticipate the future and to avert adverse events, by (1) becoming knowledgeable about the threats, (2) deciding what to do and (3) intervening to remove or counteract the threats. More specifically, the knowledge that predictive testing will provide is coined in terms of risk; measures to anticipate the future are conceived of in terms of risk reduction.

If we think of predictive testing as a tool to anticipate the future, this tool seems to reduce the meaning of anticipation to the timely identification and reduction of risks. Moreover, it transforms the future from a realm of uncertainty into something that can be 'tamed' (Hacking 1990). The DNA in one's body can be read as a sign betraying what the future may have in store for this individual (Lock 1998), and thus changes complete uncertainty into a determinate risk. In addition, this risk knowledge may help to change the course of the future: by taking risk reducing measures.

\section{Limitations and drawbacks of risk discourse}

These examples indicate that the discourse of both medical and commercial providers of predictive testing is often framed in terms of the value of risk knowledge and risk reduction. These are just examples, but we suspect that in many other contexts in which predictive DNA tests are offered 'risk-discourse' is dominant. That is a reason to ask whether this type of discourse does indeed enable potential clients to come to well considered decisions with regard to the good life. In this section we will argue that such risk discourse has serious limitations, since predictive testing often is able to reduce uncertainty to a limited extent only. More importantly, 'risk discourse' inevitably frames thinking on the good life in a particular way and thus neglects or marginalizes many alternative or additional values.

\section{Criticizing the promises of risk discourse}

The first criticism might be said to be 'internal', since it accepts the promise that predictive testing is useful and will help reduce the uncertainty of the future by producing risk knowledge, and enables a person to act and thus prevent the risk from becoming reality. Even if one agrees this is a valuable goal, one should be aware that predictive testing is able to reduce uncertainty to a limited extent only. Of course, in case of monogenetic diseases like Huntington's disease or Cystic Fibrosis knowledge of genetic status results in a clear view of what the future will bring. However, since most diseases are not caused by genes alone, but by complex, as yet unknown interactions between genes, lifestyle and environment (they are so called multifactorial diseases), genetic risks are only part of the story.

Even the more modest claim that predictive testing for common, multifactorial diseases at least produces relative certainty, since it distinguishes those with a high risk of disease from those with low risk, may be doubted. Four considerations are relevant here. First, the statistically significant differences in risk identified by genetic testing for multifactorial diseases often lack clinical significance. Janssens (2006) gives an example that is instructive in this regard. A variant of the TCFL2 gene has been identified as leading to type 2 diabetes. Although the association is quite robust (it was proven in 3 independent study populations), its clinical significance is limited. In homozygous carriers (7\% of the population) the risk of diabetes is increased from 33 to $63 \%$, which may have implications for medical advice. In heterozygous carriers, however $(38 \%$ of the population) the risk increases from 33 to $38 \%$. Thus, genetic testing for the largest part of the population would result in an increase in risk that is unlikely to lead to changes in medical advice or in one's motivation to comply with such advice.

While $5 \%$ is a statistically significant increase in risk, this need not always have significant consequences for individuals. This is particularly true for all genetic tests that focus on single genetic markers for common, multifactorial diseases (Janssens 2006, 510; Chanock and Wacholder 2002, 266). The meaning of genetic test results might be increased by producing risk profiles that combine the effects of multiple genes, but this would require extensive knowledge of gene-gene-interactions, which are currently hardly understood (Janssens and van Duijn 2006; Wright et al. 2003). 
Secondly, predictive DNA testing may produce unclear or ambiguous results. For example, new mutations may be identified, the meaning of which is unclear (van Zwieten 2008). Or families that show a history of disease clearly indicating a hereditary factor do not show any mutation. In these situations the results of DNA diagnostics and pedigree analysis may conflict (Boenink 2008). In the majority of cases of predictive DNA testing for hereditary breast/ ovarian cancer the result is ambiguous, since a BRCA mutation is found only in a small minority of families with a strong family history of breast/ovarian cancer (The Dutch Cancer Genomics Center (2005) mentions a number of 1020\%; Nelson et al. (2005) in a review for the US Preventive Services Task Force give an even lower number: in $8.7 \%$ of those families a BRCA1 or BRCA2 mutation is found). Such ambiguities increase rather than decrease uncertainty regarding the future.

Thirdly, even when the result of DNA diagnostics is clear, the risk estimate usually does not tell when and how the disease will strike. In case of predictive testing for $\mathrm{HD}$ and $\mathrm{CF}$ a positive result does impart the knowledge that one will die of a serious disease, but it does not say when the disease will strike and how long it will last. In the case of more common multifactorial diseases like hereditary breast cancer or prostate cancer predictive testing does not inform mutation carriers how serious the disease will be: will it be mild and curable, or serious and lethal? The knowledge produced by predictive testing is thus limited. Nevertheless, 'anticipated regret' motivates many people to take drastic measures they might have avoided if more had been known about the seriousness or timing of the disease (Tijmstra 2007). If they abstain from such measures, a huge amount of uncertainty is there to stay.

Finally, the interventions available for those identified to have an increased risk are not always very effective in reducing the risk of either a disease occurring or premature death due to this disease. Regular screening, which is one of the options available to carriers of a mutation that increase risk for breast/ovarian or colorectal cancer, clearly does not prevent disease from occurring, although it is supposed to contribute to survival rates. As Nelson et al. point out in their review for the US Preventive Services Task Force, evidence for reduction of mortality rate by regular screening of BRCA carriers is still lacking (Nelson et al. 2005). Moreover, even when a BRCA-mutation carrier has had preventive mastectomy a chance remains that breast cancer will strike: the surgery is thought to reduce breast cancer risk with 90\%, (Vanchieri 2005, 1032). This is not to say that interventions like regular screening and preventive surgery do not make sense. It does mean, however, that it is possible that people go to great lengths to prevent a disease -which consequently may become a very important goal in their lives- but should still live with the possibility that the disease will strike nonetheless.

In the preceding section we showed that the risk discourse used by providers of predictive DNA-testing frames the future, as well as our anticipation of the future, in a particular way: it focuses on knowledge of the magnitude of (measurable) adverse events and implies that this knowledge should lead to decisions regarding the management of these events. However, we can now conclude that the risk knowledge produced by predictive DNAdiagnostics may be of limited value only for dealing with uncertainties about the future.

\section{Criticizing the implications of risk discourse}

Next to this 'internal' type of criticism, which focuses on the limits of the present possibilities to predict and control risks, risk discourse has also invited 'external' criticism. The concept of risk has been extensively analyzed and criticized by philosophers, ethicists, cultural theorists and social scientists, both in general and in the context of health-issues. It is not our aim here to present an overview of all the debates. We will concentrate on four critiques found in this literature that we consider most relevant to DNA-diagnostics.

First of all, the risk-discourse focuses on a very limited number and type of values. The concept of 'risk' that is most commonly used in contexts of genetic diagnostics is quite narrow. 'Risks' are here most frequently understood as harms that may occur in the future, and for which a specific gene is held responsible. This 'harm' furthermore can be counted in numbers; for example, numbers of people who got the disease after a specific mutation had been found in their genes. However, this interpretation of 'harm' gives a very limited view of the ways in which people can be harmed. Not only the health and life of people is vulnerable; genetic testing may also impact on people's lives in very different ways. It may, for example, change people's experience of daily life, their perception of the future as well as their relationship to others, and to possible future siblings. While there are ethicists who make risk assessments that do take these richer aspects into account (see for example Malek and Kopelman 2007), our examples in the first section of this article raise the suspicion that this is not always common practice in the context of genetic diagnostics. Here the risk assessment that patients have to make is represented as a balance between the risk to get a disease, and the benefit of being 'saved' (See for this common narrow understanding ShraderFrechette 1998.)

Because DNA-tests affect diverse parts of human life, it is to be expected that people could profit from a richer 
evaluative vocabulary than the risk-benefit balance provides, to determine how to deal with DNA diagnostics. As pluralists have shown (Gilligan 1982; Turner 2003a, b) on the basis of empirical material, people may look at decisions-including their decisions about their health-in very different ways, starting from their diverse experiences, types of relations, cultural and religious backgrounds. It is therefore likely that a variety of values will be at stake in their deliberations about the changes that genetic tests may affect in their personal lives, (family-) relations or attitude towards the future.

This first criticism directly leads to the second one, which attacks the presumed objectivity of 'risks'. If risks refer to harms that can be counted in numbers, this gives them an aura of objectivity. Furthermore, many riskassessments attempt to establish exactly what the chance is that this harm occurs. In the context of quantitative risk assessment, for example, an attempt is made to be very precise as to how 'probable' the risk is; in this literature 'risk' is expressed in terms of a number that indicates the average annual probability that people with a specific gene got the disease, which is usually based on past statistics.

This attempt to be exact and objective is not shared or supported by all ethicists who are interested in risks. Teuber (1990), for example, offered an extensive critique of the idea that an account of 'risk' could ever be objective, and asks the question by whom risk is to be defined. Furthermore, Hansson identified a tendency of ethicists who talk about risks to turn decisions that are in fact uncertain, into decisions that are probable and therewith make them more 'manageable' (Hansson (1996, 2003). However, even though many ethicists criticize the 'objectivity' of riskassessments, providers of predictive testing tend to continue to perceive predictive testing as a means to identify objective risks: mutations predisposing to disease. In doing so, they implicitly evaluate disease as an adverse event that demands to be counter-acted, whatever one's personal perspective may be. However, if future health is considered an aspect of human life that people can interpret and value in different ways, the absolute value of health preservation seems to loose its self-evidence. In daily life, individuals may have different ideas regarding what constitutes a serious disease and when it would diminish their possibilities for a good life. This may be dependent on their personal history, and on the kinds of expectations, feelings, knowledge and evaluation they have developed during their life; but also on their perspective on what other valuable aspects of their livesbeside their health-they might be loosing, if they do everything in their power to preserve their health.

A third drawback of the risk-discourse is that it focuses primarily on harms for individuals. But, as Malek and Kopelman (2007) rightly remark, genes are shared, so they likely impact not only on individuals but also on their family members and/or future children. It seems natural to want to take the wellbeing of these (future) relatives into account (Hausman 2008; Malek 2007; Robertson and Savulescu 2001). However, it is hard to do so within a riskdiscourse. As Malek and Kopelman explain in relation to an example of Native Americans in whom a genetic susceptibility to alcoholism has been detected, it is difficult to understand effects on this group such as stigmatization and discrimination, as a 'risk'. A group lacks the body and mind that is capable of being harmed.

With this example, these authors show that the language that is often used by ethicists who talk about 'harms' and 'risks' is more apt to distinguish impacts on individuals, then it is to talk about effects on groups of people. However, while many authors -such as Malek and Kopelman, Hausman and Robertson and Savulescu- continue to use this discourse, and work round this limitation, one might also draw the conclusion that the language of 'risks' is not appropriate for the articulation and understanding of some issues that are at stake in the context of DNA-diagnostics.

The last criticism is that in the context of genetic diagnostics, as well as in the ethical risk-discourse, it is common to represent choices as decisions between two alternatives; such as taking a test or not, preserving one's health or not. This is a simplification of the choices that people face in real life. It suggests that choices are binary and that they have consequences that flow directly from this choice. But in the case of DNA-diagnostics, the relation between a choice and its effects is often not straightforward. For example, the native Americans that Malek and Kopelman mention can be confronted with the unexpected effect of stigmatization and discrimination, which is not only caused by their choice to take the DNA-test, but by a complex interplay between this decision and the characteristics of the social context in which it is taken, in which native Americans already have a hard time being respected. If the possibility of such a complex interplay between a choice and elements of the context is taken into account in the deliberation, choices quickly cease to be binary: native Americans would then understand that they do not face a binary choice between taking a test or not, but they could start to think about 'in-between' options for action, such as taking the test only under certain conditions regarding the publication or use of the test-results.

In a risk assessment the interplay between the decision to take a test and the context in which it is taken is usually left out of scope, which leads to a simplified view on choices and their consequences. But it is in this interplay that people usually realize values in their lives, or fail to do so. Deliberation therefore needs to take aspects of the context into account.

These four critiques show four ways in which the riskdiscourse-at least in the way it is used in contexts of 
genetic diagnostics-is lacking: (1) it tends to focus on a few values (health and life) and leaves too many valuable aspects of life that can be affected out of scope, (2) it wrongfully presents risks as 'objective', (3) it has difficulties considering group-effects, and (4) it simplifies choices and fails to take the relevant aspects of the context in which choosers operate into consideration.

In all these respects we think risk-discourse does not help people sufficiently to make good decisions. While the plurality of values on the basis of which people choose may be a good reason not to interfere with their decision making and to leave them free to decide for themselves (negative freedom), they are not given the necessary prerequisites to be enabled to think or do something (positive freedom). It is questionable whether people in present practices of predictive testing are given the positive freedom to dissent from the risk-benefit discourse in DNA diagnostics, if alternative discourses are lacking in the public sphere. Genetic counselling does not fill the gap, since most counselors aim to be non-directive. Moreover, the setting of counseling practices reinforces the central thought that individuals (or families, for that matter) have to decide what to do in private. Deliberation is still taking place within the walls of the consultation room, where external influences are limited and where a policy of confidentiality ensures that stories are not heard outside.

The apparent hegemony of risk discourse in providers' information on predictive testing makes it more difficult for people who feel at disease with the current practice of DNA tests because their considerations do not fit the risk discourse, to find the words to express their thoughts. The vocabularies for doing so are hardly publicly available. And if they find no words, it becomes more difficult to resist the risk-benefit style of deliberation which is common in the practice of DNA testing. This may result in more participation in DNA tests. For if one does not find ways to express dissent, what can one answer the physician who advises to take a DNA test? And how can people explain their acts to members of their family who want them to take the test?

If the only vocabulary that is publicly available is the risk-benefit discourse, it becomes harder to defend a position that is in disagreement with DNA-tests which have been developed to ward off risks. We therefore think that the deliberation processes of individuals and families considering predictive testing have much to gain from an enrichment of the public discourse. If a variety of discourses would be available in addition to the risk discourse, individuals would be enabled to broaden the types of considerations to take into account. Reading and hearing about the deliberations and experiences of people who faced similar decisions regarding predictive DNA tests is one way of becoming familiar with such a variety of discourses. It might even contribute to 'formative experiences': experiences in which a person's beliefs are gradually altered because of repeated involvement in an activity (DePaul 1993, 144-145). ${ }^{2}$ DePaul introduces this notion of 'formative experiences' when considering naïve or conservative people-who lack or actively avoid certain experiences-to point out that because of their lack of formative experiences, they are unable to develop their moral outlook in certain ways. But he acknowledges that repeated engagements with a work of art, such as a painting, a novel or a movie, may also produce alterations in one's evaluative habits.

Thinking along this line, the focus on risk in contexts of predictive DNA testing might be perceived as imposing a kind of naïveté on people. Respect for people's freedom of choice is sometimes thought to demand that insightful deliberations about the good life are securely kept in the private sphere and remain inaccessible to a broader public which is consequently unable to be formed by them. But because most people face decisions about predictive DNA tests only once in their lives, and lack the experience that would enable them to take them, we think it would be helpful to take notice of the deliberations and experiences of other people who were in a similar situation before them. Reading about experiences and deliberations of those who already did consider (and in some cases experience) predictive testing, may have similar formative effects as DePaul ascribes to repeated involvement with an artwork.

\section{Insights from empirical research}

The collection of such stories need not start from scratch. As we will show in this section, qualitative sociological and anthropological studies offer a wealth of material that could be used to this purpose. Again, we do not claim to present a systematic overview of research in this field. We selected salient examples from our own and other's

\footnotetext{
2 The term 'formative experiences' is borrowed from DePaul (1993), but similar phenomena have been described by others. Nussbaum, for example, defends the view that experiences or artworks (especially: novels) are able to influence a person's moral outlook. According to some passages in her work this happens as an immediate, powerful and overwhelming 'cataleptic impression' (pp. 263-269, Nussbaum 1990) which informs us about experiential matters-such as whom we love- and sometimes it happens over a prolonged period of involvement in an activity. This comes forwards, for example, in her approving descriptions of attempts to involve students in third world countries as a standard part of the curriculum. This helps students, according to Nussbaum, to imagine the lives of others, which is likely to change their values (pp. 79-83, Nussbaum 1997). Nussbaum believes that because such an expensive cultural encounters program may not be feasible for all students, it might be replaced by reading books. Novels also cultivate a capacity for 'sympathetic imagination' (p. 85, Nussbaum 1997).
} 
research that illustrate how empirical research into the deliberations and experiences of individuals and families who considered predictive testing might enrich professional and public discourse on the desirability of predictive testing. This empirical work offers leads for deliberation where the risk-discourse is lacking: personal stories may show that it is possible (1) to incorporate a rich set of values, (2) to acknowledge the shared character of genes, and (3) to take into account the details of the context in which testing is considered, thereby going beyond the binary options usually constructed by risk discourse. As stories about personal experiences and deliberations, moreover, they do not construct the views of the good life as objective or neutral.

\section{A rich set of values}

Regarding the set of values that is taken into account, many authors have argued that in addition to health and control, values like family relationships, love, care, solidarity, bodily integrity, femininity or having an open future should be considered when deliberating predictive testing. Opinions differ, however, on the extent to which such alternative values are already brought into play by individuals and families considering predictive testing. Older literature seems to suggest that these values are either neglected (Marteau and Richards 1996; Wexler 1996; Horstman et al. 1999; Tijmstra 2007) or redefined in terms of risk in a process of geneticization (Hallowell 1999; Finkler et al. 2003). In contrast, recently several authors have argued that clients of predictive testing are less passive than this literature suggested: they actively co-construct the practice of predictive testing in such a way that alternative values do come into play (see for example Gibbon 2002; Konrad 2005; Featherstone et al. 2006; Rowley 2007; Kelly 2009). We do not want to settle this dispute here. Let it suffice to say that in both older and more recent literature examples can be found of people who are-more and less successfully-trying to make space for other values in addition to health. We will discuss two of them.

The first is taken from Alice Wexler's book Mapping Fate (1996), but is recurring in other research as well. Wexler, a member of a family suffering from Huntington's disease (HD), describes how the introduction of genetic testing in her family was perceived as potentially affecting existing views of the future as well as feelings of solidarity. Before genetic testing was available, siblings had to face a similar future, in which HD might or might not strike. Of course this uncertainty was difficult to deal with, but at least it was a shared uncertainty, and siblings could exchange experiences and support each other in this ordeal. This bond might be broken after having predictive testing, because it might turn out that one sister is a mutation carrier, whereas the other is not. Thus, in addition to closing the future of mutation carriers, predictive testing might jeopardize solidarity between family members. In the case of the Wexlers, this was an important consideration in not taking the test.

The second example originates from field work one of us did some years ago with women considering predictive testing for breast/ovarian cancer. ${ }^{3}$ One of the women involved was Bernadette, whose sister had been diagnosed with breast cancer and was subsequently identified as a BRCA-mutation carrier. Bernadette received an invitation for predictive testing via this sister. She decided to have a test, but her reasons for doing so were not coined in terms of risk reduction and the value of health. Instead, she stressed that she wanted to show respect for her sister's attentiveness towards her; she wanted to respond to her sister's caring gesture:

"Well, that she is doing this for us, well, I think that's pretty special, and that's why I made an appointment. (...) I think it's wonderful if someone ... I can imagine that you're devastated when you suddenly have cancer, and your whole world... everything becomes uncertain; and when you still feel: my sisters should have themselves examined too, then I'm thinking you're a good person, if you're able to work that up, don't you? Yes, I think so!"

Bernadette explicitly indicates that she herself does not care about her genetic risk. Her motives, then, are coined in terms of relational goods, which are difficult to understand in terms of risk discourse. It is not the risk of loosing the good relation with her sister that moves her to engage in DNA diagnostics; what drives her to have a test is her respect for her sister's endeavor to have herself checked to protect her siblings, when she herself is ill and risks to loose her life.

In our view, experiences and stories like those of Alice Wexler and Bernadette may help other people to imagine what values are at stake and how one's life might change as an effect of DNA-tests. People who are confronted for the first time in their lives with the possibility to acquire knowledge about their genetic risk have difficulty to anticipate how this type of knowledge will affect them. And accordingly, it is hard for them to evaluate such changes. Learning how one's attitude towards the future might alter can help future clients (or potential clients) to consider how important it is for them to have an 'open future' or to know what the future has in store in order to form one's own 'lifeplan'. Likewise, stories about the role of family relations or other values besides health as a

\footnotetext{
${ }^{3}$ Methods and results of this study have been reported elsewhere (Boenink 2008).
} 
motive for predictive testing may help to come to an all inclusive, well considered judgment regarding such a test. Such stories may make readers realize in what ways they are similar or different from the person they read about, and whether they share the same values or not.

\section{The shared character of genes}

Because of the individualizing tendency of the risk discourse in which predictive testing is promoted, not all potential clients are immediately aware that test results may have implications for their relatives as well. However, people who do take part in the DNA-tests are usually quickly confronted with the shared character of their genes. The question then is how to deal with this.

For some, the shared character is a reason to opt for testing even when they may not reap great personal benefits from the risk knowledge gained. They want to contribute to the production of knowledge about the family (Hallowell 1999; Hallowell et al. 2003). For others, the family connection is an argument against having a test oneself, for example if a parent does not want to burden a child with the knowledge of having a parent at risk and/or being potentially at risk himself. As a divorced mother at risk of HD with a teenage daughter explains about her reasons for postponing the test:

"I deliberately did that ... not knowing because I wanted ... I thought if this comes out badly I might be forced into committing suicide and I have my daughter to bring up. Therefore if I didn't know and I could live with hope. It was having the hope. It was having the hope removed that was what I could not do with."(cited in Konrad, 2005, p. 74)

The family connection features even more strongly in deliberations on what to do when the test result has become available. A large body of empirical research shows that a great deal of deliberation is spent on the question whether or not to inform relatives who have not (or not yet) had a predictive test themselves, but who might have to consider whether or not to take one (siblings, children, sometimes also parents). As Featherstone et al. (2006) describe, individuals go to all lengths to decide who should or should not be told, what would be a good timing for disclosure and how they should go about telling.

Again, many different considerations are taken into account. For example, experiences of disease and death in the family may influence the willingness of individuals to tell others they may be at risk themselves. Disclosure may bring up memories of painful phases or events in a family's history, but it may also be a way to deal with the concern originating from these events. Likewise, concern about the future of the next generation can motivate disclosure, but it can equally motivate silence, because tested individuals sometimes think that knowing you might be at risk does hardly contribute to one's good life. Such judgments may be based on experiences within the family, as Carla expresses in the following quote:

"Because a lot of our family have had their children checked, most of them... But you see them sitting on it and they're dwindling on it. ... Do you know what I mean?" (cited in Featherstone et al. 2006, p. 111)

Or they may be based on experiences with persons met in disease support groups:

Claudia: "I was beginning to meet people with polycystic kidney disease and the people that hadn't known they were getting it were... seemed a lot happier than the ones that did, if you follow me" (cited in Featherstone et al. 2006, p. 111)

If telling relatives is a serious option, often an assessment is made of individual relatives' character, to determine who will and who will not be able to deal with the knowledge. Stories about such decisions to tell or not to tell may be informative, for they may draw attention of the reader towards specific characteristics of their own situation, which may be similar or differ from the one described in the story. Such a comparison broadens the imagination about what could happen if information becomes available, and enables people to make a wise decision, considering the specifics of the context they are in.

Interestingly, also parents who married into an affected family are considered in deciding whether or not to have a test and if so, how to deal with the result. Or they may be active agents in taking the decision whether or not to tell, such as in the following example, described by Konrad (2005, pp. 90-94) in her ethnographic work on families with Huntington's disease about Daisy, a woman in her mid-twenties with three young children. Daisy's mother was afflicted with HD, but her father only told Daisy and her sister years after the diagnosis had first been established. He thought it best to withhold from his children the knowledge of the character and genetic nature of the disease, as well as the difficulties he faced as their mother's caregiver. Daisy was told about the diagnosis only years after it had been formally established. In her turn, when Daisy herself decides to have a predictive test, she is tested positive, but does not tell her father about it. Like her father before her, she withholds knowledge, thinking the other will find the information too distressing. She did mention to her father that a predictive test is now available, to see his reaction, and he indicates that he does not want her to have it and if she did, he would rather not know. Explaining her reasons for not telling she says: 
"I think it would have been like... the final nail in the coffin, you know. I don't think he would have coped with that at all. I think it would have been devastating for him. It was devastating enough losing the wife that he obviously loved to bits." (cited in Konrad, 2005, p. 91)

As Konrad indicates, one might argue that Daisy repeats the lie and commits the same kind of deception by not telling. However, Daisy is not thinking about the principle of honesty, nor does she come to her decision by means of a balance of the benefits and harms of truth telling in a rational way. Her reflections on her father's best interests are motivated by a desire to be kind to him and care for him (p. 92, Konrad (2005)) Her story therefore not only shows an acknowledgment of the importance of genetic information for relatives, even to a relative who does not share the problematic gene, but also displays different types of values that can be an inspiration to other deliberators who face similar choices.

\section{Beyond binary options}

In information on predictive testing decisions are often framed as if answers are binary. To test or not to test? To disclose results to others or not to disclose? To have preventive surgery or not? This framing narrows the amount of options that people actually take into account. However, one of the observations that keep recurring in the empirical research on the ways clients actively co-shape the meaning of predictive testing is that there are many more than two types of responses to the questions posed by predictive testing. ${ }^{4}$ As has already become clear in the sections above, some individuals reflect on the issues predictive testing confronts them with in a much more multi faceted way. Decision making, deliberating and acting are often carefully geared towards the circumstances at hand. It is not so much the 'what' of the decisions that is relevant, then, but the 'how'. Under which conditions is it justified to inform relatives about test results? Under which conditions would a preventive mastectomy be a good idea?

\footnotetext{
$\overline{4}$ Interestingly, similar criticism has been voiced against the construction of ethical issues in engineering. William Lynch and Ronald Kline, for example, show that ethics of engineering case-studies usually focus on a single responsible agent, who faces a choice between two alternatives; am I going to blow the whistle -or not? Am I going to dissent with the requirement of my management -or not? On the basis of Diane's Vaughan's extensive research into the Challenger-disaster, they argue that ethics casuistry's focus needs to include 'more actions and more agents'. (pp. 198, 199, Lynch and Kline 2000) As Vaughan's study shows, there was no dramatic moment in which the engineer Boisjoly decided not to blow the whistle; rather, moral choices were made continuously within a stream of ongoing practice, by a variety of agents with different interests.
}

We want to argue that people's experiences with and stories about predictive testing can offer detailed insight into the multi-faceted ways in which they understood and dealt with the choices they were confronted with, and how the complex characteristics of their context figured in their deliberations. Let us discuss two examples from our own field work.

First, we return once more to Bernadette, the woman who coined her motivation to do a predictive test in terms of respect for her diseased sister. Not only did she not care about the risks for herself. More importantly, she made it clear that she intended to do nothing with the results. If she would turn out to have a BRCA mutation seriously increasing her chance of developing breast cancer, she did not plan to take preventive, risk reducing measures.

The test actually identified her as a BRCA-carrier. Even though all her 5 sisters had been identified as mutation carriers as well, this had not changed her feelings about preventive measures. As she had announced earlier, she did not take any regular check ups. She felt that if she would take those, the disease might actually strike, whereas refraining from preventive measures evolved from an affirmative attitude towards life that might contribute to continuing health. This attitude was further illustrated by her recent pregnancy. While recently at least some BRCAmutation carriers in The Netherlands have asked for preimplantation genetic screening because they hesitate to create children that may carry the mutation, Bernadette did not want her genetic status to interfere with her (and her partner's) desire to have a child. Although her attitude had caused some difficulties in the contacts with some of her siblings and her parents, she seemed to succeed in maintaining her 'carpe diem' approach to the good life.

Bernadette's story shows that decisions with regard to predictive testing are not binary. A person can opt to take a test, and still refrain from doing anything with the results. Such stories may be informative for other people too. Even if they do not decide to act in the same way as Bernadette does, her story shows that taking the test is not like stepping on a train that automatically leads to preventive actions. There is a series of decisions to be taken, that one may take in different ways. 5

As our second example shows, the decision to take a DNA-test or not depends very much on what 'having a predictive test' actually means. Because BRCA-testing produces a lot of negative results -only in about 10-20\% of all families diagnosed as showing a pattern of hereditary breast/ovarian cancer, a BRCA mutation is found- it was

\footnotetext{
${ }^{5}$ We do not want to argue, however, that clients in their creative coconstruction of the process of predictive testing can do anything they want: possibilities for creative co-construction of predictive testing are limited, for example, by the characteristics of the technology involved, by legal regulation or by practical procedures.
} 
decided in The Netherlands that healthy women presenting themselves for testing are asked to approach their diseased relative(s) first. Only if this diseased relative is identified as a mutation carrier, the healthy woman will be tested herself. This raises, of course, many problems with regard to whether and how to ask the diseased relatives for help.

During interviews with women considering predictive BRA-testing, held about 1 year after they first contacted a clinical geneticist about this, most of them indicated that they were not willing to proceed with predictive testing if it is dependent on the cooperation of relatives. They felt that they would use others as means towards their own ends, and refused to go along. Thus, more detailed knowledge of the context of predictive testing played an important role in their decisions.

Hearing about the ways other people perceived their options and found creative ways to deal with them may help in different ways to form a nuanced view of what actually may be at stake. Of course, the protagonists in such stories may have different values or be engaged in different relationships with partners, children, parents, siblings or other family members than those who listen to or read about them. Nonetheless, the confrontation with such differences may be helpful in perceiving and articulating one's own situation. This prevents a situation in which every individual facing genetic tests has to invent the wheel all over again.

\section{Conclusion}

As we pointed out at the start of this article, providers of predictive testing usually leave the decision whether or not to take a predictive DNA test to the individual. Both the professional ethics of genetic counselors as well as the ethics of the market place explicitly state that 'the client should decide'. Although the desire not to infringe on individuals' freedom is in itself laudable, its defendants ignore that reflection and deliberation do not take place in a void, but are predicated on the available repertoires, vocabularies, discourses. As we have shown, the information offered by providers is often coined in terms of risk and urges clients to come to a decision by weighing risks and benefits of predictive testing. Moreover, alternative discourses are hardly visible in the public domain.

In our view, personal deliberation and decision making on the good life are more likely to flourish when a rich set of vocabularies and discourses is available. Instead of relegating deliberation processes to the private sphere of home or counseling office, they should be part of the public domain. Sharing and discussing the experiences of others might help individuals and families to become aware of what it might mean for the quality of one's life to have a predictive test, and what could be relevant considerations in deciding how to deal with the possibility and reality of predictive testing.

We think empirical research on the actual deliberation processes of (potential) clients of predictive testing offers helpful stories which may support and inspire those confronted with similar situations: they point towards a rich set of values that people may use to consider their own situation, but also offer food for thought about how to deal with the pressure on family-relations that DNA-tests may cause, and they may offer a more differentiated insight into the type and diversity of decisions that could be taken. We think that such stories should be made accessible for a broad public more often, for example by including them in brochures or on websites by providers of predictive testing. Organizing support groups for individuals and families might be another way to feed people's deliberation processes with a much richer diet than the currently dominant risk discourse offers.

One might question, of course, who is responsible for such attempts to enrich public and professional discourse. In countries where predictive testing is offered in a medical-professional context, with opportunity for counseling, counselors might be much more active in this regard. In countries where predictive testing is offered in a commercial context, however, one cannot expect test providers to take this responsibility on their own. Here, some governmental intervention might be necessary to ensure that information is less one-sided. In both cases, of course, (potential) clients might take up the challenge themselves, by initiating support groups or by sharing their story in the form of magazine articles, weblogs, or even in novels and television soaps. In this way, public discussions about predictive DNA-testing and how it may affect people's lives, have a chance to become richer and more helpful to future individuals and families who face the difficult decisions that this new technology brings about.

Acknowledgments We want to thank Tsjalling Swierstra as well as two anonymous referees for their helpful comments on earlier versions of this paper. Thanks as well to Bernadette and the other women who participated in the empirical research of the first author. This research was funded by the Dutch Organization for Scientific Research NWO, which we gratefully acknowledge. We also thank NWO for funding the research of the second author, which led to this paper.

Open Access This article is distributed under the terms of the Creative Commons Attribution Noncommercial License which permits any noncommercial use, distribution, and reproduction in any medium, provided the original author(s) and source are credited.

\section{References}

Bartels, D.M., B.S. LeRoy, and A.L. Caplan. 1993. Prescribing our future. Ethical challenges in genetics counseling. New York: Aldine de Gruyter. 
Berlin, I. 1959. Two concepts of liberty. Oxford: Clarendon Press.

Boenink, M. 2008. Genetic diagnostics for hereditary breast cancerDisplacement of uncertainty and responsibility. In Genetics from laboratory to society, ed. G. de Vries and K. Horstman, 37-63. Houndmills Basingstoke: Palgrave/Macmillan.

Boenink, M. 2009. Unambiguous test results or independence? Clients, families and predictive BRCA testing in The Netherlands and the USA. Submitted.

Bosk, C.L. 1992. All god's mistakes. Genetic counseling in a pediatric hospital. Chicago: The University of Chicago Press.

Brody, B.A. 2002. Freedom and responsibility in genetic testing. Social Philosophy and Policy 19 (2): 343-359.

Cancer Genomics Center. 2005. Genen, Over kankeronderzoek, gendiagnostiek, erfelijkheidstesten en doelgerichte therapieën. Utrecht: Cancer Genomics Centerfout DNA en kanker.

Chanock, S., and S. Wacholder. 2002. One gene and one outcome? No way. Trends in Molecular Medicine 8 (6): 266-269.

Davison, C., S. Macintyre, and G.D. Smith. 1994. The potential social impact of predictive genetic testing for susceptibility to common chronic diseases: A review and proposed research agenda. Sociology of Health \& Illness 16 (3): 340-371.

DePaul, M.R. 1993. Balance and refinement; beyond coherence methods of moral inquiry. London/New York: Routledge.

Dutch Cancer Society. 2002. Hereditary breast and ovarian cancer (brochure). Amsterdam.

Featherstone, K., P. Atkinson, A. Bharadwaj, and A. Clarke. 2006. Risky relations: Family, kinship and the new genetics. Oxford: Berg.

Fine, B.A. 1993. The evolution of nondirectiveness in genetic counseling and implications of the human genome project. In Prescribing our future, ed. D.M. Bartels, B.S. LeRoy, and A.L. Caplan, 101-117. New York: Aldine de Gruyter.

Finkler, K., C. Skrzynia, and J.P. Evans. 2003. The new genetics and its consequences for family, kinship, medicine and medical genetics. Social Science and Medicine 57: 403-412.

Fost, N. 1999. Ethical implications of screening asymptomatic individuals. In New ethics for the public's health, ed. D.E. Beauchamp and B. Steinbock, 344-352. Oxford: Oxford University Press.

Gezondheidsraad. 1994. Genetische screening. Den Haag: Staatsuitgeverij.

Gibbon, S. 2002. Re-examining geneticization: Family trees in breast cancer genetics. Science as Culture 11 (4): 429-457.

Gilligan, C. 1982. In a different voice: Psychological theory and women's development. Cambridge: Cambridge University Press.

Hacking, I. 1990. The taming of chance. Cambridge: Cambridge University Press.

Hallowell, N. 1999. Doing the right thing: Genetic risk and responsibility. Sociology of Health \& Illness 21 (5): 597-621.

Hallowell, N., C. Foster, R. Eeles, A. Ardern-Jones, V. Murday, and M. Watson. 2003. Balancing autonomy and responsibility: The ethics of generating and disclosing genetic information. Journal of Medical Ethics 29: 74-83.

Hansson, S.O. 1996. Decision making under great uncertainty. Philosophy of the Social Sciences 26 (3): 369-386.

Hansson, S.O. 2003. Ethical criteria of risk acceptance. Erkenntnis 59: 291-309.

Hausman, D. 2008. Protecting groups from genetic research. Bioethics 22 (3): 157-165.

Horstman, K., G.H. de Vries, and O. Haveman. 1999. Gezondheidspolitiek in een risicocultuur. Burgerschap in het tijdperk van de 'voorspellende geneeskunde'. Den Haag: Rathenau Instituut.

Janssens, A.C.J.W. 2006. Predictive genetic testing for type 2 diabetes may raise unrealistic expectations. British Medical Journal 333: 509-510.
Janssens, A.C.J.W., and C.M. van Duijn. 2006. Towards predictive genetic testing of complex diseases. European Journal of Epidemiology 21: 869-870.

Kelly, S.E. 2009. Choosing not to choose: Reproductive responses of parents of children with genetic conditions or impairments. Sociology of Health \& Illness 31 (1): 81-97.

Konrad, M. 2005. Narrating the new predictive genetics. Ethics, etnography and science. Cambridge: Cambridge University Press.

Lock, M. 1998. Breast cancer: Reading the omens. Anthropology Today 14 (4): 7-16.

Lynch, W.T., and R. Kline. 2000. Engineering practice and engineering ethics. Science, Technology \& Human Values 25 (2): 195-225.

Malek, J. 2007. Understanding risks and benefits in research on reproductive genetic technologies. Journal of Medicine and Philosophy 32: 339-358.

Malek, J., and L.M. Kopelman. 2007. The well-being of subjects and other parties in genetic research and testing. Journal of Medicine and Philosophy 32: 311-319.

Marteau, T., and M. Richards, eds. 1996. The troubled helix. Social and psychological implications of the new human genetics. Cambridge: Cambridge University Press.

Nelson, H.D., L. Hoyt Huffman, R. Fu, and E. Harris. 2005. Genetic risk assessment and BRCA mutation testing for breast and ovarian cancer susceptibility: Systematic evidence review for the US. Preventive services task force. Annals of Internal Medicine 143: 355-361.

Nussbaum, M.C. 1990. Love's knowledge. In Love's knowledge; essays on philosophy and literature, ed. M.C. Nussbaum. New York/Oxford: Oxford University Press.

Nussbaum, M.C. 1997. Cultivating humanity. A classical defense of reform in liberal education. London: Harvard University Press.

Parthasarathy, S. 2005. Architectures of genetic medicine: Comparing genetic testing for breast cancer in the USA and the UK. Social Studies of Science 35 (1): 5-40.

Parthasarathy, S. 2007. Building genetic medicine. Breast cancer, technology, and the comparative politics of health care. Cambridge (Mass.): MIT Press.

Robertson, S., and J. Savulescu. 2001. Is there a case in favour of predictive genetic testing in young children? Bioethics 15 (1): 26-49.

Rowley, E. 2007. On doing 'being ordinary': Women's accounts of BRCA testing and maternal responsibility. New Genetics and Society 26 (3): 241-250.

Shrader-Frechette, K. 1998. Risk. In Routledge encyclopedia of philosophy, Version 1. London/New York: Routledge.

Teuber, A. 1990. Justifying risk. Daedalus; Proceedings of the American Academy of Arts and Sciences 119 (4): 1-20.

Tijmstra, T. 2007. 'At least we tried everything': About binary thinking, anticipated decision regret, and the imperative character of medical technology. Journal of Psychosomatic Obstetrics and Gynaecology 28 (3): 131.

Turner, L. 2003a. Bioethics in a multicultural world: Medicine and morality in pluralistic settings. Health Care Analysis 11 (2): 99-117.

Turner, L. 2003b. Bioethics and religions: Religious traditions and understandings of morality, health, and illness. Health Care Analysis 11 (3): 181-197.

van Zwieten, M. 2008. In Genetics from laboratory to society, ed. G. de Vries and K. Horstman, 17-36. Houndmills Basingstoke: Palgrave/Macmillan.

Vanchieri, C. 2005. Risk reduction works for BRCA mutation carriers-With heavy costs. Journal of the National Cancer Institute 97 (14): 1032-1033. 
Wexler, A. 1996. Mapping fate. A memoir of family, risk, and genetic research. Berkeley: University of California Press.

Wright, A., B. Charlesworth, I. Rudan, A. Carothers, and H. Campbell. 2003. A polygenic basis for late-onset disease. Trends in Genetics 19 (2): 97-106.

\section{Websites}

www.myriadtests.com.

www.genosolutions.com. 